\title{
PERSEPSI KARYAWAN BANK SYARIAH TERHADAP KONSEP KNOWLEDGE MANAGEMENT DAN CELESTIAL MANAGEMENT
}

\section{EMPLOYEE PERCEPTION OF BANK SYARIAH ON THE CONCEPT OF KNOWLEDGE MANAGEMENT AND CELESTIAL MANAGEMENT}

\author{
Denthy Anisha1a; Afiaty Kurniasih²; Adi Rahmannur Ibnu ${ }^{3}$ \\ 1aProgram Studi Perbankan Syariah Fakultas Ekonomi Islam Universitas Djuanda, Jl. Tol \\ Ciawi No. 1, Kotak Pos 35 Bogor 16720, e-mail: dentianisa18@gmail.com \\ 2Program Studi Perbankan Syariah Fakultas Ekonomi Islam Universitas Djuanda, Jl. Tol \\ Ciawi No. 1, Kotak Pos 35 Bogor 16720 \\ ${ }^{3}$ Program Studi Perbankan Syariah Fakultas Ekonomi Islam Universitas Djuanda, Jl. Tol \\ Ciawi No. 1, Kotak Pos 35 Bogor 16720
}

\begin{abstract}
This study aims to determine the perception of employees of Islamic banks on the concept of knowledge management and celestial management. There is a positive perception or not in the both concepts, that leads to differences in perceptions towards the knowledge and value of spirituality of employees in a competitivr banking industry. The research methodolog used in this research Chi-Square descriptive quantitative by collecting data using questionnaires and interviews. The results of this study indicate that there is a positive perception between knowledge managemen and celestial management perception which is identified from the calculated chi-square value which is greater than the chisquare meaning the second hypothesis; there is not difference regarding the perception of employees of Islamic banks on the concept of knowledge management and celestial management, is accepted.
\end{abstract}

Keywords: Perception, Knowledge Management, Celestial Management.

\begin{abstract}
ABSTRAK
Penelitian ini bertujuan untuk mengetahui persepsi karyawan bank syariah terhadap konsep knowledge management dan celestial management. Apakah terdapat persepsi positif atau tidak pada kedua konsep, sehingga akan menimbulkan perbedaan persepsi untuk meningkatkan pengetahuan dan nilai spiritualitas pada karyawan dalam meningkatkan bisnis di dunia perbankan. Metodologi penelitian yang digunakan dalam penelitian ini menggunakan teknik Chi-Square deskriptif kuantitatif dengan pengumpulan data menggunakan angket kuesioner dan wawancara. Hasil penelitian ini menunjukan bahwa terdapat persepsi positif terhadap konsep knowledge management dan celestial management yang diketahui bahwa nilai chi-square hitung lebih besar dari nilai chi-square dan pada Hipotesis kedua tidak terdapat perbedaan persepsi karyawan bank syariah terhadap konsep knowledge management dan celestial management.
\end{abstract}

Kata Kunci : Persepsi, Knowledge Management, Celestial Management

Denty Anisha. 2018. Persepsi Karyawan Bank Syariah terhadap Konsep Knowledge Management dan Celestial Management. Jurnal Nisbah 4 (2): 182-197. 


\section{PENDAHULUAN}

\begin{tabular}{lrr}
\multicolumn{2}{c}{ Perusahaan harus menyadari } \\
begitu penting mengelola dan \\
memanfaatkan manajemen dalam suatu \\
perusahaan, cepat atau lambat \\
perusahaan yang memiliki konsep \\
manajemen yang tertata akan
\end{tabular}
menciptakan aset yang sangat berharga yaitu pengembangan SDM Islam dibidang ilmu pengetahuan, konsep manajemen pengetahuan atau dikenal dengan (knowledge management), menjadi sesuatu yang sangat menentukan dalam meningkatkan keilmuan dibidang pekerjaan, oleh karena itu diperlukan cara agar dapat mengintegrasikan pengetahuan yang ada disertai kerangka untuk mengembangkan SDM Islam (Esthi, 2011: 135). Seperti yang dikatakan oleh Fatwan dalam (Ikrahmawati, 2016: 5) dimana faktor utama dalam bidang bisnis bukan era informasi lagi melainkan sudah berubah ke era pengetahuan (knowledge).

Knowledge management secara efektif pada SDM tidak hanya menciptakan keunggulan bersaing tetapi meningkatkan kinerja organisasi dalam memperoleh knowledge yang dimiliki oleh setiap SDM. Pengetahuanpengetahuan tersebut harus diciptakan salah satunya dengan cara mengelola konsep pengetahuan melalui knowledge management (Kusuma, 2013:162). Konsep knowledge management dapat menjadi dukungan dalam meningkatkan kepuasaan perusahaan dibidang pengetahuan, walaupun knowledge berasal dari masing-masing pemikiran individu namun hal inilah menjadi tugas suatu perusahaan untuk membangun konsep manajemen yang dibutuhkan sehingga perbankan mampu berkompetisi dan menunjukkan eksistensinya sebagai perusahaan yang mempunyai konsep knowledge management yang unggul (Rodin, 2013:35).
Selain itu, dibutuhkan sebuah konsep manajemen yang bisa membangun dan menciptakan keberadaan SDM Islam melalui spiritualitas dalam kehidupan seharihari, seluruh kehidupan di dunia ini memang diatur oleh Allah SWT maka dengan adanya konsep manajemen Islam (celestial management) yang didasarkan pada penafsiran nilai dari prinsip Ilahiah yang turun dari langit melalui firman Allah SWT maupun sabda utusan-Nya serta diaplikasikan lah dikehidupan manusia (Trimulanto, 2016: 199). Pengaruh nilai spiritualitas pada suatu organisasi dapat dilihat dari penelitian Walker (2011) dalam (Sulkan, 2016:1) yang menyebutkan bahwa ketika seorang bekerja dengan iman maka nilai pekerjaannya adalah ibadah maka dari itu, seseorang akan menghasilkan job outcomes yang memuaskan bagi sebuah perusahaan dan dirinya sendiri.

Budaya kerja berbasis spiritualitas diharapkan dapat meningkatkan budaya organisasi, nilai-nilai Islam dapat membentuk komitmen SDM dalam menyelesaikan tugasnya maupun menghadapi problem, baik di dalam perusahaan maupun di luar perusahaan, konsep celestial management sebaiknya terus berkembang dalam jangka panjang karena semakin membuktikan bahwa Islam memiliki model dan cara tersendiri untuk memajukan ekonomi umat melalui mekanisme kerja dalam berorganisasi bank Islam (Rahmat, 2016:23).

Penerapan kedua konsep manajemen tersebut sebenarnya sudah dikelola sejak lama, namun masih sesuai dengan kemampuan dan pola pikir dari suatu bank syariah tersebut, seperti "Penerapan konsep knowledge management pada karyawan di PT Bank Muamalat Indonesia TBK Cabang Makassar (Utami, 2016:72)". "Program pelatihan, pengembang kinerja dan produktivitas pegawai pernah dijalankan di United Bank Limited (UBL) Peshawar 
City, KPK, pakistan (Tahir, 2014:86)". Konsep manajemen knowledge management sudah dilaksanakan di BSM Cabang cirebon (Prayitno, 2015:1). BNI Syariah cabang cirebon (Suharta, 2007:1) dan Bank Sulut Cabang Utama Manado dengan indikator personal knowledge, job procedure dan teknologi (Sumual, 2013:620). Sedangkan pada Bank Jatim Syariah konsep manajemen yang diterapkan berbasis prinsip syariah dalam kegiatan operasionalnya melarang pemungutan bunga bank (Meilina, 2015:2) dan dalam tesis (Piliyanti, 2010:1) yang berjudul "Penerapan konsep the celestial management (Studi pada Bank Muamalat Cabang Yogyakarta)".

\section{MATERI DAN METODE}

\section{Persepsi}

Persepsi hakikatnya proses penilaian individu terhadap suatu objek atau persepsi merupakan aktivitas mengindra, mengintegrasikan dan memberikan sebuah penilaian pada objek-objek fisik maupun stimulus sosial sekitarnya. Sensasi yang ada pada lingkungan tersebut akan diolah bersama dengan hal-hal yang telah dipelajari sebelumnya baik hal itu berupa harapanharapan nilai-nilai, sikap, ingatan dan lain sebagainya. (Adiyansyah, 2013: 10).

Menurut Walgito dalam Widya (2003: 2) adanya indikator dalam persepsi, meliputi:

a) Komponen kognitif atau (komponen perseptual) berkaitan dengan dasar pengetahuan, pandangan, keyakinan, informasi mengenai suatu yang berhubungan dengan bagaimana seseorang memberikan persepsinya terhadap objek yang diserap kemudian diterima oleh panca indera, baik penglihatan, pendengaran dan lain-lain.

b) Komponen afektif (komponen emosional) berhubungan dengan rasa senang atau tidak senang terhadap objek tertentu sama dengan sikap. Rasa senang merupakan hal yang positif dan rasa tidak senang merupakan hal yang negatif, sifatnya lebih evaluatif membentuk pemahaman yang cepat mengenai pengalaman yang telah dimiliki individu.

c) Komponen konatif (komponen perilaku atau action component) atau tindakan yang berhubungan dengan kecenderungan bertindak terhadap objek tertentu. Komponen ini menunjukkan intensitas sikap, besar kecilnya kesiapan seseorang terhadap penilaian objeknya.

\section{Manajemen Sumber Daya Manusia (MSDM)}

Dapat dikatakan sebagai wadah dalam penyatuan tenaga kerja yaitu pencapaian tujuan pada suatu perusahaan dengan cara mengembangkan motivasi dan meningkatkan kinerja sdm melalui tahap pengorganisasian, perencanaan, pelatihan dan pengembangan sehingga dapat mendorong sumber daya manusia agar lebih baik dari sebelumnya untuk mencapai titik tujuan yang sudah direcanakan dan diharapkan oleh perusahaan (Febrisma, 2016: 938).

\section{Knowledge}

Pengetahuan merupakan salah satu aset perusahaan yang tidak berwujud. Pengetahuan mencakup teori dan konsep yang mendukung atau pengalaman yang akan membuat seseorang secara diamdiam lebih mendalami berbagai hal untuk melakukan tugasnya agar lebih baik (Ikrahmawati, 2016: 9).

\section{Jenis-Jenis Pengetahuan}

Menurut (Ekadiansyah, 2013: 103) pengetahuan dibagi ke dalam dua jenis yaitu tacit knowledge dan exsplicit knowledge, berikut penjelasannya:

1) Tacit knowledge yaitu pengetahuan yang bersifat personal yang berasal dari pakar. Merupakan pengalaman 
pribadi seseorang yang sulit untuk dibagikan atau dikomunikasikan kepada orang lain, pengetahuan tacit pada dasarnya pengetahuan yang dipraktekkan, seperti perasaan pribadi, intuisi, bahasa tubuh, pengalaman fisik dan lain-lain (Ekadiansyah, 2013: 103; Dewi, 2013: 27; Ikrahmawati, 2016: 12).

2) Explicit knowledge yaitu, pengetahuan yang bersifat formal merupakan teori tentang sesuatu, yaitu pengetahuan yang mudah dibagikan kepada orang lain seperti pengetahuan yang memang sudah ada dalam bentuk buku, jurnal yang tersimpan dalam sebuah flashdisk, memori card, rekaman vidio yang memang sudah terdokumentasikan sebelumnya, sehingga mudah untuk dibagikan kepada orang lain (Ekadiansyah, 2013: 103; Dewi, 2013: 27; Ikrahmawati, 2016: 12).

\section{Knowledge Management}

Manajemen

pengetahuan

merupakan peran penting dalam memperbaiki suatu perusahaan melalui pengetahuan, pengalaman dan kreativitas dari karyawan dalam perusahaan. Dengan menerapkan konsep knowledge management perusahaan akan mampu mengetahui sumber utama aset intangible perusahaan, sehingga akan lebih mudah untuk menentukan pengetahuan yang dibutuhkan oleh perusahaan dan mempertimbangkan pengetahuan seperti apa yang berpotensi untuk dikembangkan (Silvianita, 2016: 1850).

Indikator yang akan diteliti:

1) Pendidikan

Menurut (Alam, 2016: 8) pendidikan pada hakikatnya adalah usaha untuk mengubah dan mengembangkan tingkah laku diri sendiri di dalam maupun luar sekolah yang berlangsung seumur hidup, maka penyelenggaraan pendidikan menjadi tanggung jawab kita bersama mulai dari keluarga, masyarakat, dan pemerintah.

Menurut (Wirawan, 2016: 3). Dimensi tingkat pendidikan meliputi:

a. Dimensi pendidikan formal, dengan pendidikan terakhir yang ditamatkan oleh setiap karyawan bank syariah mulai dari SD, SMP, SMA dan perguruan tinggi.

b. Dimensi pendidikan Informal, melalui sikap dan kepribadian yang dibentuk oleh keluarga dan lingkungan misalnya, seperti: studi keluar (kuliah, pertukaran tenaga kerja antar perusahaan) yang dilakukan oleh karyawan untuk memperoleh gelar dari ilmu pengetahuan yang sama atau dengan menambah wawasan yang lebih luas dan memperoleh jenjang karir individu.

2) Pelatihan

Pelatihan merupakan cara perusahaan untuk meningkatkan kinerja dari suatu karyawan, pelatihan diberikan dalam jangka relatif pendek, pelatihan harus dilaksanakan secara kontinyu dan satu arah sesuai dengan target yang diharapkan oleh perusahaan (Ragawanti, 2014: 2).

Pelatihan yang dapat dilakukan oleh perusahaan dalam bentuk: In house training atau training eksternal salah satunya coaching dimana program bimbingan secara nyata yang diberikan oleh atasan kepada bawahan untuk meningkatkan skill karyawan yang akan melibatkan seseorang yang sudah berpengalaman untuk memberikan bimbingan kepada orang yang belum berpengalaman mengenai berbagai hal yang terkait dengan pekerjaan, dapat dilaksanakan oleh trainer (seorang pemandu) khusus dari dalam perusahaan atau luar perusahaan bisa juga dari keduanya (Rozalinda, 2016: 121).

3) Pengembangan

Pengembangan bertujuan untuk mengembangkan karir sdm, proses berkembang dalam menyelesaikan 
pekerjaan yang akan dicapai oleh karyawan, dapat menambah pengetahuan dan memperluas pengalaman dalam pekerjaan yang lebih fleksibel (Wahyuni, 2014: 3).

Adanya fase pengembangan merupakan lamanya waktu untuk memenuhi persyaratan perpindahan dari satu posisi ke tempat yang lain yang diinginkannya. Pengembangan dapat dilakukan melalui rotasi jabatan yaitu menugaskan karyawan untuk melakukan berbagai jabatan, melalui proses pemindahan secara horizontal. Memiliki jabatan yang satu level bahkan dilakukan dengan yang diatas atau bawah bidang pekerjaan, kemudian berpindah tempat dari bidang satu ke bidang pekerjaan yang lain bahkan keluar perusahaan, sesuai dengan jangka waktu yang telah ditentukan (Wahyuni, 2014: 3).

\section{Celestial Management}

Merupakan konsep manajemen langit yang didasarkan oleh prinsipprinsip Ilahiah dengan aturan Islam yang berlandasan dalil-dalil Alquran dan Hadis Rasulloh SAW, konsep ini akan diaplikasikan dalam kehidupan seharihari oleh aktivitas manusia termasuk aktivitas usaha bisnis. Celestial management merupakan sebuah usaha untuk melahirkan nilai dari kecerdasan spiritualitas dari seorang individu karena konsep Islam ini menyakini kehidupan yang kekal hanyalah akhirat (Rosnaeni, 2016: 10).

Menurut Amin A. R. (2006) konsep the calestial management dibagi dalam tiga dominan tempat yaitu:

\section{1) A Place of Worship (tempat} menyembah dalam pekerjaan)

Ketika akan memulai pekerjaan dan memandang tempat pekerjaan sebagai suatu tempat ibadah, dalam proses pekerjaan harus didasarkan rasa keikhlasan dan senantiasa selalu mengingat kepada Allah SWT. Tempat menyembah dalam pekerjaan, diturunkan kembali kedalam empat atribut yaitu ZIKR (Zero Base, Iman, Konsiten, Result Oriented):

a) Zero Base yaitu niat dan ketulusan dalam bekerja, karyawan bank harus mempunyai niat yang sungguhsungguh agar tujuan dari pekekerja hanya untuk mencari ridha Allah.

b) Iman yaitu yakin, optimis karena iman (penuh keyakinan) ketika akan melakukan hal-hal yang tidak di ridoi oleh Allah akan selalu ingat bahwa Allah selalu berada disisinya dan tidak mau melakukan perbuatan yang tidak disukai oleh Allah.

c) Konsistensi yaitu bersikap istiqomah dan kaffah, dalam menjalankan pekerjaan harus istiqomah dan terus maju bisa memperbaiki kekurangan yang dimiliki, memegang kepercayaan dari setiap nasabahnya, menciptakan prestasi yang dapat ditunjukan dalam pengembangan produk dan inovasi yang ada.

d) Result Oriented yaitu dalam melakukan pekerjaan sebagai perwujudan ibadah, selalu mengharapkan (keridhaan Allah SWT) tidak pernah peduli apapun yag dibicarakan orang lain karena seorang bankir syariah mengetahui apa yang disebut falah dan akan menyeimbangkan kebahagiaan dirinya di dunia maupun di akhirat.

2) A Place of Wealth (tempat kesejahteraan dalam pekerjaan)

Sebagai orang muslim tempat bekerja dinilai sebagai tempat kesejahteraan yang mulia untuk para pekerja berkumpul di dalamnya, terciptanya keseimbangan antara materi maupun non-material dan keseimbangan dalam bekerja akan menciptaan proses yang adil.

Tempat sebagai kesejahteraan, diturunkan kembali kedalam empat atribut utama yaitu: PIKR (Power, Information, Knowledge, dan Reward). 
a) Power Sharing merupakan (pembagian kekuasaan) kekompakan yang harus dimiliki oleh seorang individu, kerjasama yang baik akan meningkatkan kekuatan dari setiap individu sehingga akan menciptakan karakteristik dari seorang individu.

b) Information yaitu ketika sumber daya manusia mempunyai akses informasi yang baik, internal dan eksternal guna kemajuan teknologi yang ada dan sangat cepat untuk memperbesar jaringan antar nasabah, meningkatkan inovasi dan produk yang beredar cepat dengan adanya sumber informasi.

c) Knowledge Sharing yaitu ketika seseorang bisa saling mentransfer dan menerima ilmu dari anggota satu ke anggota lainnya, mulai dari pengetahuan, keterampilan dan kegiatan koordinasi mengenai produk bisa dilakukan dimana saja sehingga akan bermanfaat dan menciptakan nilai yang unggul dalam kemajuan pekerjaanya.

d) Reward Sharing yaitu pembagian hadiah dalam bentuk prestasi karena melakukan pekerjaan dengan sukses, maka dari itu akan menjadi percuma jika tidak adanya sharing pengetahuan dan keterampilan karena jika ketiga pembagian tersebut berjalan baik akan muncul rewards untuk para karyawan dan akan memicu karyawan untuk menjadi lebih baik.

3) A Place of Warfare (tempat peperangan dalam bekerja)

Seorang memandang bahwa tempat pekerjaanya sebagai tempat pertempuran yang akan membawanya dalam kebaikan dan menunjukkan hal yang positif untuk memajukan sebuah perusahaan dalam kualitas dirinya dan akan menghasilkan individu yang pantang menyerah dalam setiap pekerjaannya akan menjadi sukses dan maju bahkan akan menjadi modal yang sangat berguna. Konsep ini menghasilkan komunitas mikir atau yang selalu berproses dalam berpikir, yang diturunkan kedalam empat atribut utama MIKR (Militan, Intelek, Kompetittif, Regeneratif), yaitu:

a) Militan merupakan leader dalam team kerja sebagai modal utama untuk mendorong individu untuk memberikan motivasi yang ada agar selalu bersemangat dan penuh gairah dalam menyelesaikan pekerjaan.

b) Intelek merupakan penyelesaikan masalah yang cukup rumit namun, individu tersebut menggunakan skill sehingga selalu memberikan keterampilan yang baik.

c) Kompetitif merupakan tahap penyelesaian yang tidak hanya melalui penguasaan knowledge dan informasi namun dibutuhkan kemauan untuk berperan serta terjun ke lapangan dan menyumbangkan kinerja terbaiknya untuk suatu organisasi.

d) Regenaratif merupakan kesempatan yang sama untuk mendapatkan apa yang diinginkan jadi tidak terpaku pada satu individu saja bisa diwariskan kepada generasi selanjutnya.

Indikator yang akan diteliti:

1. Budaya Organisasi

Budaya organisasi adalah seperangkat sistem nilai (values), keyakinan (beliefs) atau norma yang telah diterapkan, disepakati dan diikuti oleh seluruh anggota organisasi, dukungan manajemen sebagai pedoman dalam pemecahan masalah yang ada (Dwinastiti, 2016: 15; Alam, 2016: 8) .

$$
\text { Budaya organisasi dapat }
$$

meningkatkan jiwa spiritual karyawan salah satunya karyawan harus mempunyai sikap responsbility yaitu suatu tanggung jawab dari setiap pelaksanaan tugas dan kewajiban yang dikerjakan. Tanggung jawab dapat 
diperuntukan kepada Allah SWT, sesama manusia dan diri sendiri sehingga akan menciptakan sikap intergritas yang tinggi dimana, kepribadian atau karakter dari karyawan akan terlihat dari kepercayaan, kejujuran, kebenaran dan kesetiaan serta diperlukan komunikasi yang kuat untuk memastikan hubungan antara karyawan memang didasari komunikasi yang tulus (Dwinastiti, 2016: 20).

2. Nilai-Nilai Islam

Nilai-nilai Islam adalah sifat atau hal yang berasal dari Alquran dan Hadis sebagai pedoman penentuan tingkah laku seseorang yang berguna bagi manusia untuk bekal hidup di dunia dan di akhirat, lebih mengarah kepada keberhasilan seseorang (Dwinastiti, 2015: 10) yang mencakup akidah, ahlak dan ibadah. Akidah sama seperti keimanan, ahlak sebagai wujud perilaku etika dan perbuatan, dan ibadah merupakan wujud perbuatan dari keimanan. Keseluruhan nilai-nilai syariah dapat dicerminkan dengan melaksanakan shalat lima waktu secara tepat waktu, melaksanakan Shalat duha, tadarusan, dan lain-lain. Shalat dikatakan dalam hadis Nabi sebagai tiang agama, shalat dapat mewakili nilai-nilai Islam yang akan membentuk budaya yang unggul dan menghasilkan kinerja yang optimal (Pasaribu, 2015: 73).

3. Komitmen

Komitmen organisasi adalah kepercayaan terhadap nilai-nilai organisasi, berusaha semaksimal mungkin untuk kemajuan perusahaan yaitu keinginan menjadi anggota organisasi agar bersangkutan lebih dari sekedar keanggotaan formal. Karyawan dapat melaksanakan tugas dengan mengedepankan kepentingan perusahaan, melaksanakan pelayananFh kepada nasabah dengan tidak melihat strata harta atau jabatan dan selalu membantu kesuksesan dari kemajuan perbankan (Arifin, 2010: 176; Hendrawan, 2016: 91).

\section{Uji Instrumen}

Uji instrumen dalam penelitian ini menggunakan uji validitas dan reliabilitas. Uji validitas merupakan tindakan yang dilakukan peneliti untuk menguji secara bertahap hasil pengisian kuesioner yang telah diisi oleh para responden (Lestari, 2014: 45; Wadah, 2016: 200; Sugiyono, 2013: 172). Hal tersebut dilakukan untuk mengukur ketepatan dan kecermatan hasil dari jawaban yang telah diberikan responden melalui kuesioner sehingga data yang diperoleh peneliti akan sesuai dengan diadakannya penelitian tersebut.

Uji reliabilitas adalah pengukuran yang dilakukan oleh peneliti terhadap suatu ketepatan dari variabel yang telah ditentukan . Uji realibilitas dalam penelitian ini menggunakan metode alfa cronbach's, yang tolak ukur atau patokan yang digunakan untuk menafsirkan korelasi antara skala yang dibuat dengan indikator-indikator yang ada (Sugiyono, 2013: 178; Lestari, 2015: 48; Wadah, 2016: 200).

\section{Test Chi-Kuadrat (Chi-Square)}

Chi Square adalah salah satu penggunaan statistik untuk memutuskan apakah sebuah hipotesis ditolak atau tidak. Jika t hitung lebih besar dari t tabel maka H0 ditolak sebaliknya jika t hitung lebih kecil dari t tabel maka H0 diterima (Alhifni, 2012: 41; Wahyuni, 2014: 43; Abdurahman, 2016: 37). Dengan derajat kebebasan atau degree of freedom $(\mathrm{df})=$ $\mathrm{N}$ - k. N adalah jumlah total pengamatan (data sampel), $\mathrm{k}$ adalah jumlah parameter yang diestimasi (variabel).

Hipotesis dapat diuji dengan menggunakan rumus:

$\mathrm{X}^{2}=\underline{(\mathrm{Fo}-\mathrm{Fh})^{2}}$

Keterangan:

$\mathrm{X}^{2}=$ chi kuadrat

Fo = frekuensi yang diobservasikan

$\mathrm{Fh} \quad=$ frekuensi yang diharapkan 


\section{Populasi dan Sampel}

Populasi adalah wilayah generalisasi yang terdiri atas objek atau subjek yang mempunyai kualitas dan karakteristik tertentu yang telah ditetapkan oleh peneliti untuk dipelajari kemudian dan ditarik kesimpulannya (Sugiyono, 2013: 80).

Sampel merupakan bagian dari populasi. Teknik pengambilan sampel yang digunakan adalah probability sampling dimana, seluruh bagian anggota dari populasi memiliki hak dan opportunity yang sama sebagai sampel, kemudian dipilih metode simpel random sampling untuk dapat menentukan sampel yang diinginkan yakni teknik untuk memperoleh sampel secara langsung dari setiap unit sampling. (Abdurrahman, 2016: 32).

\section{Objek dan Lokasi Penelitian}

Objek penelitian ini karyawan Bank Muamalat Indonesia Kantor Cabang Bogor Jl.Raya Pajajaran No.165, Bantarjati, Bogor Utara, Kota Bogor, Jawa Barat 16143.

\section{Teknik Pengumpulan Data}

Dalam penelitian ini, teknik pengumpulan data yang digunakan adalah kuesioner. Kuesioner adalah salah satu cara pengumpulan data dalam suatu penelitian. Pengumpulan data ini dilakukan dengan cara membuat pernyataan yang sesuai dengan permasalahan yang sedang diteliti, dimana responden dapat menjawab pada lembar yang telah disediakan dengan mudah dan akurat (Suprapto, 2017: 99). Kuesioner dalam penelitian ini menggunakan skala likert, yaitu skala pengukuran yang berhubungan dengan pernyataan tentang sikap responden terhadap sesuatu.

Wawancara dilakukan dengan mengajukan pertanyaan secara lisan dan tertulis terhadap individu atau kelompok yang sedang diteliti, teknik pengumpulan data dengan wawancara dilakukan kepada karyawan BMI sebanyak 2 orang untuk memperkuat data.

\section{HASIL DAN PEMBAHASAN}

\section{Uji Validitas dan Reliabilitas}

Uji reliabilitas dari semua indikator menggunakan Cronbach Alpha. Kuesioner dinyatakan reliabel jika nilai koefisien alpha lebih besar $>0,6$. Hasil nilai koefisien dapat dilihat pada tabel berikut:

Tabel 1. Reliability Statistics

\begin{tabular}{|l|l|}
\hline Cronbach's Alpha & N of Items \\
\hline 966 & 30 \\
\hline
\end{tabular}

Sumber : Data diolah,2018

Tabel diatas memiliki Cronbach Alpha sebesar 0,966 di atas 0,60 maka instrumen dinyatakan reliabel.

Pengujian validitas bertujuan untuk mencerminkan secara tepat dan fakta dari yang diukur oleh peneliti.Pada pengujian validitas menggunakan uji dua pihak dengan taraf signifikan 0.06 dengan kriteria, jika $r$ hitung $\geq r$ tabel maka dinyatakan valid dan jika $r$ hitung < $r$ tabel maka dinyatakan tidak valid. Hasil uji validitas dengan SPSS 22 menunjukkan bahwa nilai uji validitas $\geq$ dari 0.312, keseluruhan variabel dari A1 sampai dengan B15 memiliki nilai $\geq$ dari 0.312 , hasil ini menunjukkan bahwa 30 pertanyaan dari 2 variabel yang digunakan dalam kuesioner untuk mengetahui persepsi karyawan terhadap konsep knowledge management dan celestial management adalah valid.

\section{Analisis Chi-Square}

Analisis ini digunakan untuk menguji seberapa besar taraf signifikansi yang diperoleh dari jawaban responden agar hasil yang diperoleh dapat teruji secara akurat. Berikut ini adalah perhitungan dan analisis chi square bagi variabel persepsi karyawan perbankan syariah terhadap konsep knowledge management dan celestial management dalam hal menguji hipotesis di bawah ini: 
$\mathrm{H}_{0} \quad$ :Tidak terdapat persepsi positif terhadap konsep knowledge management dan celestial management.

$\mathrm{H}_{1}$ :Terdapat persepsi positif terhadap konsep knowledge management dan celestial management.

$\mathrm{H}_{0} \quad$ :Tidak terdapat perbedaan persepsi terhadap konsep knowledge management dan celestial management.

$\mathrm{H}_{2}$ :Terdapat perbedaan persepsi terhadap konsep knowledge management dan celestial management.

Knowledge management adalah kerangka organisasi sebagai fokus disiplin ilmu yang mencakup ekonomi bisnis. Knowledge management salah satu keunggulan kompetitif tertinggi untuk mengolah suatu perusahaan (Elias, 2007) sedangkan celestial management adalah nilai-nilai dalam bingkai spiritual yang semestinya menjadi motivasi dan ruh sebuah bisnis, visi langit yang berupa spiritualitas yang kita terima dalam bentuk firman-firman tuhan maupun sabda utusan-nya (Riawan, 2004).

Tabel 2. Persepsi Karyawan Bank Syariah terhadap Konsep Knowledge

Management Indikator Pendidikan

\begin{tabular}{|l|c|c|c|c|c|}
\hline Kategori & $\mathrm{F}_{\mathrm{o}}$ & $\mathrm{F}_{\mathrm{h}}$ & $\left(\mathrm{f}_{\mathrm{o}}-\mathrm{f}_{\mathrm{h}}\right)$ & $\left(\mathrm{f}_{\mathrm{o}}-\mathrm{f}_{\mathrm{h}}\right)^{2}$ & $\begin{array}{l}\left(\mathrm{f}_{\mathrm{o}}-\mathrm{f}_{\mathrm{h}}\right)^{2} \\
\mathrm{~F}_{\mathrm{h}}\end{array}$ \\
\hline $\begin{array}{l}\text { Sangat } \\
\text { Setuju }\end{array}$ & 10 & 2,5 & 7,5 & 56,25 & 22,5 \\
\hline Setuju & 21 & 5,25 & 15,75 & $\begin{array}{l}248,0 \\
6\end{array}$ & 47,24 \\
\hline $\begin{array}{l}\text { Kurang } \\
\text { Setuju }\end{array}$ & 8 & 2 & 6 & 36 & 18 \\
\hline $\begin{array}{l}\text { Tidak } \\
\text { Setuju }\end{array}$ & 1 & 0,25 & 0,75 & 0,56 & 2,24 \\
\hline $\begin{array}{l}\text { Sangat } \\
\text { Tidak } \\
\text { Setuju }\end{array}$ & 0 & 0 & 0 & 0 & 0 \\
\hline \multicolumn{1}{|c|}{ Jumlah } & & & & & 89,98 \\
\hline
\end{tabular}

Berdasarkan hasil penelitian pada tabel 2 diperoleh perhitungan chi-square hitung sebesar 89,98. Dengan degree of freedom atau $\mathrm{df}=\mathrm{N}-\mathrm{k}$, yang mana $\mathrm{N}$ adalah jumlah total pengamatan (data sampel), $\mathrm{K}$ adalah jumlah parameter yang diestimasi (variabel), maka berdasarkan $\mathrm{df}=40-3=37$ dengan taraf signifikansi sebesar 5\%, maka diperoleh nilai chi-square tabel sebesar 52,19 .

Dimana konsep knowledge management adalalah konsep yang dimiliki atau diciptakan oleh suatu perusahaan dalam menciptakan nilai kerja ataupun melacak keberadan aset tidak berwujud dalam SDM salah satunya melalui pendidikan, bank muamalat mendirikan konsep knowledge management untuk meningkatkan knowledge karyawan dan hasil dari wawancara menunjukan bahwa pendidikan yang diadakan di Bank Muamalat sudah diatur oleh manajemen BMI. Menurut responden, untuk bekerja di Bank Muamalat sendiri saat ini pendidikan yang diharuskan lulusan minimal D3, S1 dan S2. Jika akan menjadi Front liner lulusan D3 dan leader marketing min $\mathrm{S} 1$, peraturan tersebut sudah ditetapkan oleh pihak manajemen. Untuk pertukaran tenaga kerja dan seminar perusahaan belum melakukannya sampai keluar, jadi masih dilakukan di dalam perusahaan.

Dengan demikian, dapat diketahui bahwa nilai chi-square hitung lebih besar dari nilai chi-square tabel $(89,98>$ 52,19). Dengan demikian H0 ditolak dan H1 diterima, artinya terdapat persepsi positif terhadap konsep knowledge management dari Indikator pendidikan. Hal tersebut berbanding lurus dengan perhitungan angka penafsiran dalam skala likert di atas, yang berada pada rata-rata jawaban "setuju".

Tabel 3. Persepsi Karyawan Bank Syariah terhadap Konsep Knowledge Management Indikator Pelatihan

\begin{tabular}{|l|c|c|c|c|c|}
\hline \multicolumn{1}{|c|}{ Kategori } & $\mathrm{F}_{\mathrm{o}}$ & $\mathrm{F}_{\mathrm{h}}$ & $\left(\mathrm{f}_{\mathrm{o}}-\mathrm{f}_{\mathrm{h}}\right)$ & $\left(\mathrm{f}_{\mathrm{o}}-\mathrm{f}_{\mathrm{h}}\right)^{2}$ & $\frac{\left(\mathrm{f}_{\mathrm{o}}-\mathrm{f}_{\mathrm{h}}\right)^{2}}{\mathrm{~F}_{\mathrm{h}}}$ \\
\hline Sangat Setuju & 18 & 6 & 12 & 144 & 24 \\
\hline Setuju & 20 & 6,66 & 13,34 & 177,95 & 26,71 \\
\hline $\begin{array}{l}\text { Kurang } \\
\text { Setuju }\end{array}$ & 2 & 0,66 & 1,34 & 1,79 & 2,71 \\
\hline Tidak Setuju & 0 & 0 & 0 & 0 & 0 \\
\hline $\begin{array}{l}\text { Sangat Tidak } \\
\text { Setuju }\end{array}$ & 0 & 0 & 0 & 0 & 0 \\
\hline \multicolumn{1}{|c|}{ Jumlah } & & & & & 53,42 \\
\hline
\end{tabular}


Berdasarkan hasil penelitian pada tabel 3 diperoleh perhitungan chi-square hitung sebesar 53,42. Dengan degree of freedom atau $\mathrm{df}=\mathrm{N}-\mathrm{k}$, yang mana $\mathrm{N}$ adalah jumlah total pengamatan (data sampel), k adalah jumlah parameter yang diestimasi (variabel), maka berdasarkan $\mathrm{df}=40-3=37$, dengan taraf signifikansi sebesar 5\%, maka diperoleh nilai chisquare tabel sebesar 52,192.

Dimana konsep knowledge management adalah konsep manajemen pengetahuan yang diberikan langsung oleh perusahaan dalam mengasah knowledge karyawan melalui pelatihan sama dengan bank muamalat konsep ini sudah dilakukan untuk menambah ataupun mengasah kemampuan dari seorang karyawan bank dan hasil dari wawancara menunjukan bahwa pelatihan yang diadakan di bank muamalat sudah diatur oleh manajemen BMI. Menurut responden, untuk karyawan yang baru masuk diadakan program pelatihan PROUMAT (Program Orientasi Bank Muamalat) yang dilakukan 4 hari sampai dengan 1 minggu, selain itu karyawan melakukan training kurang lebih sampai 3 bulan dan diberikan knowledge tentang produkproduk perbankan yang diberikan langsung dari dalam perusahan namun khusus tentang perbankan syariah biasanya motivator langsung dari pusat.

Dengan demikian, dapat diketahui bahwa nilai chi-square hitung lebih besar dari nilai chi-square tabel $(53,42>$ 52,192). Dengan demikian HO ditolak dan $\mathrm{H} 1$ diterima, oleh karena itu terdapat persepsi positif terhadap konsep knowledge management dari indikator pelatihan. Hal tersebut berbanding lurus dengan perhitungan angka penafsiran dalam skala likert di atas, yang berada pada rata-rata jawaban "sangat setuju".
Tabel 4. Persepsi Karyawan Bank Syariah terhadap Konsep Knowledge

Management Indikator Pengembangan

\begin{tabular}{|l|c|c|c|c|c|}
\hline Kategori & $\mathrm{F}_{\mathrm{o}}$ & $\mathrm{F}_{\mathrm{h}}$ & $\left(\mathrm{f}_{\mathrm{o}}-\mathrm{f}_{\mathrm{h}}\right)$ & $\left(\mathrm{f}_{\mathrm{o}}-\mathrm{f}_{\mathrm{h}}\right)^{2}$ & $\frac{\left(\mathrm{f}_{\mathrm{o}}-\mathrm{f}_{\mathrm{h}}\right)^{2}}{\mathrm{~F}_{\mathrm{h}}}$ \\
\hline $\begin{array}{l}\text { Sangat } \\
\text { Setuju }\end{array}$ & 9 & 3 & 6 & 36 & 12 \\
\hline Setuju & 25 & 8,33 & 16,67 & 277,88 & 33,35 \\
\hline $\begin{array}{l}\text { Kurang } \\
\text { Setuju }\end{array}$ & 6 & 2 & 4 & 16 & 8 \\
\hline $\begin{array}{l}\text { Tidak } \\
\text { Setuju }\end{array}$ & 0 & 0 & 0 & 0 & 0 \\
\hline $\begin{array}{l}\text { Sangat } \\
\text { Tidak } \\
\text { Setuju }\end{array}$ & 0 & 0 & 0 & 0 & 0 \\
\hline Jumlah & & & & & 53,35 \\
\hline
\end{tabular}

Berdasarkan hasil penelitian pada tabel 4 diperoleh perhitungan chi-square hitung sebesar 53,35. Dengan degree of freedom atau $\mathrm{df}=\mathrm{N}-\mathrm{k}$, yang mana $\mathrm{N}$ adalah jumlah total pengamatan (data sampel), k adalah jumlah parameter yang diestimasi (variabel), maka berdasarkan $\mathrm{df}=40-3=37$, dengan taraf signifikansi sebesar 5\%, maka diperoleh nilai chisquare tabel sebesar 52,19.

Dimana konsep knowledge management adalah konsep manajemen pengetahuan yang dapat memberikan manfaat banyak salah satunya melalui pengembangan dari seorang karyawan sama seperti konsep yang diberikan oleh bank muamalat mereka berfikir jika SDM bank muamalat berkembang pesat, hal tersebut akan membantu dalam proses berkembangnya perusahaan dan hasil dari wawancara menunjukan bahwa pengembangan yang diadakan di bank muamalat sudah diatur oleh manajemen BMI. Menurut responden, pengembangan seperti rotasi jabatan itu hanya dilakukan di dalam perusahaan saja dan dilakukannya hanya persatu divisi, misalnya seorang karyawan memegang divisi funding maka akan di rolling menjadi divisi divisi financing. Berbeda dengan jalur pejabat adanya program pendidikan sortcors MODP (Muamalat Officer Depholopment Program) MODP funding, MODP operation, MODP audit, 
MODP bace umum. Dapat diorientasikan kepada orang-orang yang akan dipromosikan jabatannya.

Dengan demikian, dapat diketahui bahwa nilai chi-square hitung lebih besar dari nilai chi-square tabel $(53,35>$ 52,19). Dengan demikian HO ditolak dan H1 diterima, dengan demikian terdapat persepsi positif terhadap konsep knowledge management dari indikator pengembangan. Hal tersebut berbanding lurus dengan perhitungan angka penafsiran dalam skala likert di atas, yang berada pada rata-rata jawaban "setuju".

Tabel 5. Persepsi Karyawan Bank Syariah terhadap Konsep Celestial Management Indikator Budaya Organisasi

\begin{tabular}{|l|c|c|c|c|c|}
\hline \multicolumn{1}{|c|}{ Kategori } & $\mathrm{F}_{\mathrm{o}}$ & $\mathrm{F}_{\mathrm{h}}$ & $\left(\mathrm{f}_{\mathrm{o}}-\mathrm{f}_{\mathrm{h}}\right)$ & $\left(\mathrm{f}_{\mathrm{o}}-\mathrm{f}_{\mathrm{h}}\right)^{2}$ & $\begin{array}{c}\left(\mathrm{f}_{\mathrm{o}}-\mathrm{f}_{\mathrm{h}}\right)^{2} \\
\mathrm{~F}_{\mathrm{h}}\end{array}$ \\
\hline $\begin{array}{l}\text { Sangat } \\
\text { Setuju }\end{array}$ & 16 & 5,33 & 10,67 & 113,84 & 21,35 \\
\hline Setuju & 23 & 7,66 & 15,34 & 235,31 & 30,71 \\
\hline $\begin{array}{l}\text { Kurang } \\
\text { Setuju }\end{array}$ & 1 & 0,33 & 0,67 & 0,44 & 1,33 \\
\hline $\begin{array}{l}\text { Tidak } \\
\text { Setuju }\end{array}$ & 0 & 0 & 0 & 0 & 0 \\
\hline $\begin{array}{l}\text { Sangat } \\
\text { Tidak } \\
\text { Setuju }\end{array}$ & 0 & 0 & 0 & 0 & 0 \\
\hline Jumlah & 40 & & & & 53,39 \\
\hline
\end{tabular}

Berdasarkan hasil penelitian pada tabel 5 diperoleh perhitungan chi-square hitung sebesar 53,39 Dengan degree of freedom atau $\mathrm{df}=\mathrm{N}-\mathrm{k}$, yang mana $\mathrm{N}$ adalah jumlah total pengamatan (data sampel), k adalah jumlah parameter yang diestimasi (variabel), maka berdasarkan $\mathrm{df}=40-3=37$, dengan taraf signifikansi sebesar 5\%, maka diperoleh nilai chisquare tabel sebesar 52,19.

Dimana konsep celestial management adalah nilai-nilai dalam bingkai spiritual yang semestinya menjadi motivasi dan ruh sebuah bisnis, manajemen langit sebagai upaya untuk menurunkan visi langit agar tersebar di bumi, visi langit yang berupa spiritualitas yang kita terima dalam bentuk firmanfirman tuhan maupun sabda utusan-nya sebagaimana hasil dari wawancara menunjukan bahwa budaya organisasi yang berhubungan dengan konsep celestial management menerapkan Innamal Amalu Bin Niat artinya setiap pekerjaan yang dilakukan di Bank Muamalat bernilai ibadah. Menurut responden, budaya organisasi Bank Muamalat kepada atasan mapun bawahan berjalan baik, dengan adanya zaman elektronik via Whatsaap merupakan budaya organisasi dalam suatu perusahaan berjalan dua arah, contoh adanya informasi dari pusat ke kantor cabang sangat cepat hanya membutuhkan waktu beberapa menit sudah sampai itu menandakan adanya budaya organisasi yang terjalin dan koordinasi antar rekan kerja maupun atasan itu berjalan dengan baik di Bank Muamalat KC Bogor.

Dengan demikian, dapat diketahui bahwa nilai chi-square hitung lebih besar dari nilai chi-square tabel $(53,39>$ 52,19). Dengan demikian HO ditolak dan H1 diterima, artinya terdapat persepsi positif terhadap konsep knowledge management dari indikator pengembangan. Hal tersebut berbanding lurus dengan perhitungan angka penafsiran dalam skala likert di atas, yang berada pada rata-rata jawaban "sangat setuju".

Tabel 6. Persepsi Karyawan Bank Syariah terhadap Konsep Celestial Management Indikator Nilai-Nilai Islam

\begin{tabular}{|l|c|c|c|c|c|}
\hline Kategori & $\mathrm{F}_{\mathrm{o}}$ & $\mathrm{F}_{\mathrm{h}}$ & $\left(\mathrm{f}_{\mathrm{o}}-\mathrm{f}_{\mathrm{h}}\right)$ & $\left(\mathrm{f}_{\mathrm{o}}-\mathrm{f}_{\mathrm{h}}\right)^{2}$ & $\frac{\left(\mathrm{f}_{0}-\mathrm{f}_{\mathrm{h}}\right)^{2}}{\mathrm{~F}_{\mathrm{h}}}$ \\
\hline $\begin{array}{l}\text { Sangat } \\
\text { Setuju }\end{array}$ & 18 & 6 & 12 & 144 & 24 \\
\hline Setuju & 21 & 7 & 14 & 196 & 28 \\
\hline $\begin{array}{l}\text { Kurang } \\
\text { Setuju }\end{array}$ & 1 & $\begin{array}{c}0,3 \\
3\end{array}$ & 0,67 & 0,44 & 1,33 \\
\hline $\begin{array}{l}\text { Tidak } \\
\text { Setuju }\end{array}$ & 0 & 0 & 0 & 0 & 0 \\
\hline $\begin{array}{l}\text { Sangat } \\
\text { Tidak } \\
\text { Setuju }\end{array}$ & 0 & 0 & 0 & 0 & 0 \\
\hline Jumlah & 40 & & & & 53,33 \\
\hline
\end{tabular}


Berdasarkan hasil penelitian pada tabel 6 diperoleh perhitungan chi-square hitung sebesar 53,33. Dengan degree of freedom atau $\mathrm{df}=\mathrm{N}-\mathrm{k}$, yang mana $\mathrm{N}$ adalah jumlah total pengamatan (data sampel), k adalah jumlah parameter yang diestimasi (variabel), maka berdasarkan $\mathrm{df}=40-3=37$, dengan taraf signifikansi sebesar 5\%, maka diperoleh nilai chisquare tabel sebesar 52,19.

Dimana konsep celestial management adalah nilai-nilai dalam bingkai spiritual yang semestinya menjadi motivasi dan ruh sebuah bisnis, manajemen langit sebagai upaya untuk menurunkan visi langit agar tersebar di bumi, visi langit yang berupa spiritualitas yang kita terima dalam bentuk firmanfirman tuhan maupun sabda utusan-nya sebagaimana hasil dari wawancara menunjukan bahwa nilai-nilai Islam yang berhubungan dengan konsep celestial management menerapkan Innamal Amalu Bin Niat jadi lebih kepada kepentingan ibadah yang dilakukan di bank muamalat. Menurut responden nilai-nilai Islam dalam pelaksanaan shalat dhuha seperti karyawan datang lebih awal dari jam kerja yaitu pukul 08:00-17:00 WIB. Pelaksanaan shalat 5 waktu pada shalat Zuhur dan Asar, karyawan Bank Muamalat melaksanakan dengan on-time ketika sudah adzan langsung dikerjakan karena pimpinan kepala cabang BMI menerapkan karyawan shalat tepat pada waktunya dan diwajibkan untuk laki-laki shalat di mesjid, perempuan di mushola. Setiap hari jumat pada saat karyawan laki-laki shalat jumat karyawan perempuan melaksanakan pengajian walaupun tidak setiap minggu tapi setiap bulan sekali pasti ada pengajian untuk perempuan pada hari jumat dan untuk seluruh karyawan adanya pengajian rutin satu bulan sekali biasanya dilakukan pada sore hari dari jam 04:00 - 05:00 dihadiri oleh seluruh karyawan dari mulai pimpinan cabang sampai bawahan, kegiatan ini tidak hanya di BMI KC Bogor namun kegiatan ini disemua BMI. Kegiatan lain yang masih menyangkut dengan nilai-nilai Islam disini adalah adanya Qiyamual (program keislaman) yang langsung diintruksikan oleh direksi pusat ke kantor cabang yang diberikan budget khusus dan pelaksanaannya karyawan perempuan dapat melakukan dirumah sedangkan untuk karyawan laki-laki bisa ikut serta. Pelaksanaan Qiyamual dilakukan di dalam kantor seperti shalat tahajud, shalat subuh berjamaah dan tadarusan kegiatan ini biasanya dilakukan pada malam minggu, kami juga mempunyai grup tahsin yang dilaksanakan pada sore hari.

Dengan demikian, dapat diketahui bahwa nilai chi-square hitung lebih besar dari nilai chi-square tabel $\quad 53,33>$ 52,19). Dengan demikian HO ditolak dan H1 diterima, yaitu terdapat persepsi positif terhadap konsep celestial management dari indikator nilai-nilai Islam. Hal tersebut berbanding lurus dengan perhitungan angka penafsiran dalam skala likert di atas, yang berada pada rata-rata jawaban "sangat setuju".

Tabel 7. Persepsi Karyawan Bank Syariah terhadap Konsep Celestial Management Indikator Komitmen

\begin{tabular}{|l|c|c|c|c|c|}
\hline Kategori & $\mathrm{F}_{\mathrm{o}}$ & $\mathrm{F}_{\mathrm{h}}$ & $\left(\mathrm{f}_{\mathrm{o}}-\mathrm{f}_{\mathrm{h}}\right)$ & $\left(\mathrm{f}_{\mathrm{o}}-\mathrm{f}_{\mathrm{h}}\right)^{2}$ & $\begin{array}{c}\left(\mathrm{f}_{\mathrm{o}}-\mathrm{f}_{\mathrm{h}}\right)^{2} \\
\mathrm{~F}_{\mathrm{h}}\end{array}$ \\
\hline $\begin{array}{l}\text { Sangat } \\
\text { Setuju }\end{array}$ & 15 & 5 & 10 & 100 & 20 \\
\hline Setuju & 23 & 7,66 & 15,34 & 235,31 & 30,71 \\
\hline $\begin{array}{l}\text { Kurang } \\
\text { Setuju }\end{array}$ & 2 & 0,66 & 1,34 & 1,79 & 2,71 \\
\hline $\begin{array}{l}\text { Tidak } \\
\text { Setuju }\end{array}$ & 0 & 0 & 0 & 0 & 0 \\
\hline $\begin{array}{l}\text { Sangat } \\
\text { Tidak } \\
\text { Setuju }\end{array}$ & 0 & 0 & 0 & 0 & 0 \\
\hline Jumlah & 40 & & & & 53,42 \\
\hline
\end{tabular}

Berdasarkan hasil penelitian pada tabel 7 diperoleh perhitungan chi-square hitung sebesar 53, 42 Dengan degree of freedom atau $\mathrm{df}=\mathrm{N}-\mathrm{k}$, yang mana $\mathrm{N}$ adalah jumlah total pengamatan (data sampel), k adalah jumlah parameter yang 
diestimasi (variabel), maka berdasarkan $\mathrm{df}=40-3=37$, dengan taraf signifikansi sebesar 5\%, maka diperoleh nilai chisquare tabel sebesar 52,19.

Dimana konsep celestial management adalah nilai-nilai dalam bingkai spiritual yang semestinya menjadi motivasi dan ruh sebuah bisnis, manajemen langit sebagai upaya untuk menurunkan visi langit agar tersebar di bumi, visi langit yang berupa spiritualitas yang kita terima dalam bentuk firmanfirman tuhan maupun sabda utusan-nya sebagaimana hasil dari wawancara menunjukan bahwa komitmen yang berhubungan dengan konsep celestial management seperti Innamal Amalu Bin Niat. Jadi lebih kepada kepentingan ibadah, yang dilakukan di bank muamalat. Menurut responden, semua karyawan BMI mempunyai komitmen dalam menyelesaikan pekerjaan maupun target masing-masing dalam beraktivitas, komitmen ke atasan dan perusahaan juga terjalin dengan baik.

Dengan demikian, dapat diketahui bahwa nilai chi-square hitung lebih besar dari nilai chi-square tabel $(53,42>$ 52,192). Dengan demikian HO ditolak dan H1 diterima, artinya terdapat persepsi positif terhadap konsep celestial management dari indikator komitmen. Hal tersebut berbanding lurus dengan perhitungan angka penafsiran dalam skala likert di atas yang berada pada rata-rata jawaban "sangat setuju".

\section{Hubungan Indikator Pendidikan, Pelatihan, Pengembangan, Budaya Organisasi, Nilai-Nilai Islam dan Komitmen}

Dengan menelusuri respon karyawan bank syariah di Bank Muamalat Indonesia KC Bogor untuk mengetahui persepsi karyawan bank syariah terhadap konsep knowledge management dan celestial management, maka dalam hal menguji hipotesis di bawah ini:
$\mathrm{H}_{0}$ : indikator pendidikan, pelatihan, pengembangan, budaya organisasi, nilainilai Islam dan komitmen tidak terdapat persepsi positif terhadap konsep knowledge management dan celestial management.

$\mathrm{H}_{1}$ : indikator pendidikan, pelatihan, pengembangan, budaya organisasi, nilainilai Islam dan komitmen terdapat persepsi positif terhadap konsep knowledge management dan celestial management.

$\mathrm{H}_{0}$ :Tidak terdapat perbedaan persepsi terhadap konsep knowledge management dan celestial management.

$\mathrm{H}_{2}$ :Terdapat perbedaan persepsi terhadap konsep knowledge management dan celestial management.

Berdasarkan hasil penelitian diperoleh perhitungan chi-square hitung sebesar 356,89. Dengan degree of freedom atau $\mathrm{df}=\mathrm{N}-\mathrm{k}$, dimana $\mathrm{N}$ yaitu jumlah total pengamatan (data sampel), $\mathrm{k}$ adalah jumlah parameter yang diestimasi (variabel), maka berdasarkan $\mathrm{df}=40-3=37$, dengan taraf signifikansi sebesar 5\%, maka diperoleh nilai chisquare tabel sebesar 52,19. Dengan demikian, dapat diketahui bahwa nilai chi-square hitung lebih besar dari nilai chi-square tabel $(356,89>52,19)$. Maka dapat diketahui bahwa hipotesis pertama adalah $\mathrm{H}_{0}$ ditolak dan $\mathrm{H}_{1}$ diterima, bahwa indikator pendidikan, pelatihan, pengembangan dari variabel knowledge management dan indikator budaya organisasi, nilai-nilai Islam, komitmen dari variabel celestial management. Terdapat persepsi positif terhadap konsep knowledge management dan celestial management dan berdasarkan hasil perhitungan chi square pada konsep knowledge management dari indikator pendidikan, pelatihan, pengembangan dan celestial management dari indikator budaya organisasi, nilai-nilai Islam, komitmen menunjukan bahwa hipotesis kedua adalah $\mathrm{H}_{0}$ diterima dan $\mathrm{H}_{2}$ ditolak, artinya tidak terdapat perbedaan 
persepsi terhadap konsep knowledge management dan celestial management.

Dalam konsep celestial karyawan disebut mujahid yaitu menjalankan konsep ekonomi yang sehalan dengan jiwa syariah, tempat bekerja diharapkan akan menjadi tempat pertempuran dalam mekajukan ekonomi umat dan seseorang yang beriman tidak akan membuat kesalahan yang tidak disukai allah dan tidak akan pernah menyelesaikan pekerjaannya dengan tidak penuh tanggung jawab.

\section{KESIMPULAN DAN SARAN}

\section{Kesimpulan}

Setelah peneliti melakukan penelitian pada Bank Muamalat Indonesia KC Bogor mengenai persepsi karyawan bank syariah terhadap konsep knowledge management dan celestial management, terdapat beberapa kesimpulan yang dapat dijelaskan, yaitu:

1. Terdapat persepsi positif terhadap konsep knowledge management dan celestial management di bank muamalat konsep knowledge management penting untuk diterapkan, karena meningkatkan kemajuan dari manajemen perusahaan selain itu perusahaan dapat memperbaiki kinerja karyawan melalui knowledge pengalaman dan kreatifitas dalam perusahaan dan berdasarkan hasil perhitungan chi square pada konsep knowledge management indikator pendidikan, pelatihan, pengembangan nilai chisquare hitung lebih besar dari nilai chi-square tabel $(356,89>52,19)$. Maka dapat diketahui bahwa $\mathrm{H}_{0}$ ditolak dan $\mathrm{H}_{1}$ diterima dan pada konsep celestial management konsep ini sudah diaplikasikan dalam kehidupan sehari-hari oleh aktivitas karyawan dalam usaha bisnisnya, konsep celestial management merupakan konsep langit untuk melahirkan nilai dari kecerdasan spiritualitas seorang karyawan dan konsep ini diyakini akan menciptakan kehidupan yang kekal di akhirat.

2. Berdasarkan hasil perhitungan chi square pada celestial management dari indikator budaya organisasi, nilai-nilai Islam, komitmen nilai chisquare hitung lebih besar dari nilai chi-square tabel (356, $89>52,19)$ Maka dapat diketahui bahwa $\mathrm{H}_{0}$ ditolak dan $\mathrm{H}_{1}$ diterima.

\section{Saran}

1. Diharapkan hasil penelitian ini mampu menjadi acuan kepada peneliti selanjutnya yang akan meneliti dengan konsep yang sama, namun dengan indikator yang berbeda agar diperoleh hasil penelitian yang lebih variatif mengenai konsep knowledge management dan celestial management di perbankan syariah.

2. Bagi peneliti selanjutnya dapat menambah jumlah objek penelitian, tidak hanya di bank muamalat saja bisa dengan bank-bank syariah lain.

\section{DAFTAR PUSTAKA}

Abdurrahman, Rivan. (2016). Persepsi Praktisi Perbankan Syariah Mengenai Penerapan Teknologi PREAUTHORIZED DEBIT Sebegai FEE BASED INCOME Pada Bank Syari'ah. Fakultas Ekonomi dan Bisnis Syariah Universitas Djuanda.

Adiyansyah, Susi. (2013). Persepsi Pengusaha Produk Tekstil terhadap Perbankan Syariah (Studi kasus di Kabupaten Sukabumi). Fakultas Ekonomi dan Bisnis Syariah Universitas Djuanda.

Alam, A. P. (2016). Analisis Kinerja Karyawan pada PT Bank Syariah Mandiri Cabang Aksara Medan Ditinjau dari Manajemen Syariah. Analytica Islamica, Vol. 5 No. 1, 1-19. 
Alhifni, Anas. (2012). Persepsi Santri terhadap Perbankan Syariah. Fakultas Ekonomi dan Bisnis Syariah Universitas Djuanda.

A. Riawan, Amin. (2006). The Celestial Mangement. Jakarta: Senayan Abadi Publishing. Cet.V.

Arifin, Noor. (2010). Analisis Budaya Organisasional terhadap Komitmen Kerja Karyawan Dalam Peningkatan Kinerja Organisasional Karyawan pada Koperasi BMT di Kecamatan Jepara. Jurnal Ekonomi \& Pendidikan, Vol. 8 No. 2, November, 173-192.

Dewi, M.T. (2013). Meningkatkan Keunggulan Kompetitif Perusahaan dengan Penerapan Knowledge Management (Manjemen Pengetahuan). Jurnal JIBEKA Vol. 7 No. 3, Agustus, 26-32 .

Dwinastiti, Suci.E. (2015). Pengaruh Nilai-Nilai Islam dan Budaya Organiasasi Terhadap Produktivitas Kerja Karyawan Mina Swalayan Yogyakarta. Jurusan Manajemen Dakwah Fakultas Dakwah dan Komunikasi Universitas Islam Negeri Sunan Kalijaga Yogyakarta.

Ekadiansyah, Evri. (2013). Implementasi Knowledge Management System pada Pengembangan Sumber Daya Manusia. Journal, Vol.5 No.2, Juni, $102-117$.

Esthi, R.B. (2011). Analisis Tingkat Penerapan Manajemen Pengetahuan dalam Membangun Organisasi Berbasis Pengetahuan (Studi Kasus PT Trubus Mitra Swadaya SE-JABODETABEK). Jurnal Manajemen dan Organisasi Vol. II, No. 2, Agustus, 135-153.

Febrisma, R. F. (2016). Pengaruh Pengembangan Sumber Daya Manusia terhadap Kinerja Pegawai pada Kantor Badan Kepegawaian Daerah Provinsi Kalimantan Timur. E-Journal Ilmu Administrasi Bisnis, Vol. 4, ISSN 2355-5408, 937-946.
Hendrawan, Yan.K. (2016). Pengaruh Pelatihan, Pengembangan dan Motivasi terhadap Peningkatan Kinerja Pegawai dengan Mediasi Komitmen Organisasi. Jurnal Bisnis \& Manajemen, Vol. 16, No. 1, 89-104.

Ikrahmawati. (2016). Pengaruh Knowledge Management terhadap Kinerja Karyawan (Studi Pada PT. Kumala Motor Sejahtera Abadi Kendari). Kendari: Universitas Ekonomi dan Bisnis.

Kusuma, F.S.D dan Devie. (2013). Analisa Pengaruh Knowledge Management terhadap Keunggulan Bersaing dan Kinerja Perusahaan. Business Accounting Review, Vol. 1 No. 2, 161 171.

Lestari, Wiji. (2015). Efektivitas Pengelolaan Wakaf Tunai di Badan Wakaf Indonesia. Fakultas Ekonomi dan Bisnis Syariah Universitas Djuanda.

Meilina, Dewi. (2015). Studi Pemahaman Nilai Syariah pada Praktisi Syariah di Bank Jatim Syariah cabang Surabaya. Sekolah Tinggi Ilmu Ekonomi Perba Surabaya.

Pasaribu, P.N.dkk. (2011). Hubungan Nilai-Nilai Islami, Budaya dan Kinerja Sumber Daya Insani Bank Muamalat Indonesia. Manajemen IKM, 2011, 73-80, Vol. 6 No. 1, ISSN 2085-8418.

Piliyanti, I. (2010). Membangun Budaya Organisasi Bisnis Syari'ah (Studi Pada Bank Muamalat Indonesia). Jurnal Pemikiran dan Penelitian Ekonomi Islam Vol. 1 Edisi. I, Mei, 27-38.

Prayitno, Hadi. (2015). Pengaruh Budaya Organisasi terhadap Produktivitas Kerja Karyaan Pada bank BSM (Bank Syariah Mandiri) cabang Cirebon. Institut Agama Islam Negeri (IAIN) Syekh Nurjati Cirebon.

Rahmat, I. (2016). The Celestial Management: Ikhtiar Mewujudkan 
Budaya Organisasi Islam. Edisi Januari-Juni, 19-39.

Ragawanti, E. Dkk. (2014). Pengaruh On The Job Training dan Off The Job Training terhadap Kinerja Karyawan Studi pada karyawan Tetap PR.Sejahtera Abadi). Jurnal Administrasi Bisnis (JAB) Vol. 8 No. 2, Maret, 1-9.

Rodin, Rhoni. (2013). Penerapan Knowledge Management di Perpustakaan (Studi Kasus di Perpustakaan STAIN Curup). Khizanah Al-hikmah Vol. 1 No.1, Januari-Juni, ISSN 2354-9629, 35-46.

Rosnaeni, Y.S. (2016). Implementasi The Celestial Management di CV.Outra Mina Ngaglik Sleman Yogyakarta. Jurusan Manajemen Dakwah Fakultas Dakwah dan Komunikasi Universitas Islam Negeri Sunan Kalijaga Yogyakarta.

Rozalinda. (2016). Konsep Manajemen Sumber Daya Manusia : Implementasi pada Industri Perbankan Syariah. Jurnal Lembaga Keuangan dan Perbankan Vol. 1, No.1, Januari-Juni, 108-124.

Silvianita, V. V. (2016). Pengaruh Knowledge Sharing Terhadap Kinerja Organisasi Pada Badan Lingkungan Hidup Provinsi Sumatera Utara. e-Proceeding of Management : Vol.3 No.2, Agustus, ISSN : 2355-9357 , 1848-1855.

Sugiyono. (2013). Metodologi penelitian kombinasi. Bandung: Alfabeta.

Sulkan, E.P. (2016). Internalisasi Nilai Spiritual dalam Mengubah Konsep Diri Karyawan (Studi Kasus Pelaksanan Spiritual Capital Management PT.Telkom Indonesia di Datel Salatiga). Thesis. Salatiga: Universitas Satya Wacana.
Sumual, Alvianus K. (2013). Pengaruh Knowledge management dan Corporate Culture terhadap Inovasi (Studi Pada Bank Sulut Cabang Utama Manado). Jurnal EMBA Vol.1 No.3, Juni, ISSN 2303-1174, 617-625.

Suprapto, H. (2017). Metodologi Penelitian Untuk karya Ilmiah. Yogyakarta: Gosyen Publishing.

Trimulanto. (2016). Urgensi Penerapan Celestial Management bagi Sumber Daya Manusia Di Bank Syariah. Vol. 1 No. 1, Mei - Oktober , 197-212.

Utami, S.R, Dkk. (2016). Strategi Penerapan Knowledge Management pada Karyawan PT Bank Muamalat Indonesia TBK Cabang Makasar. Jurnal Analisis, Juni 2016, Vol. 5 No. 1, ISSN 2303-100X : $72-77$.

Wadah, R. 2016. Pengaruh Sistem Manajemen Mutu ISO 9001: 2008 Terhadap Kinerja Amilin Di Baznas. Jurnal Syarikah ISSN 2442-4420 Vol. 2 Nomor 1, Juni, 193-213.

Wahyuni, Dwi. Dkk. (2014). Pengaruh Pengembangan Karier terhadap Prestasi Kerja Karyawan (Studi pada Karyawan Tetap PT.Astra International, TBK Daihatsu Malang). Jurnal Administrasi Bisnis (JAB) Vol. 8 No. 1, Februari, 1-10.

Widya, Nur.A dan Suwarno,Wiji. (2013). Persepsi Pemustaka tentang Sikap Pustakawan pada Layanan Sirkulasi di Perpustakaan Daerah Jepara. Jurnal Ilmu Perpustakaan. Vol. 2, No. $4,10-17$.

Wirawan, K.E.I. Dkk. (2016). PengaruhTiingkat Pendidikan dan Pengalaman Kerja terhadap Kinerja Karyawan. e-Journal Bisma Universitas Pendidikan Ganesha Jurusan Manajemen Vol. 4, hal 1-9. 